\title{
Pengembangan Aplikasi Mutaba'ah untuk Evaluasi Ibadah Harian Berbasis Android
}

\author{
Guntoro (12018092) ${ }^{a, 1}$, Ardiansyah (0523077902) ${ }^{\text {b,2 }}$ \\ a,b Program Studi Teknik Informatika Universitas Ahmad Dahlan \\ J1. Ringroad Selatan, Kragilan, Tamanan, Kec. Banguntapan, Bantul,,Yogyakarta 55191 \\ ${ }^{1}$ guntoromomo@gmail.com ; ${ }^{2}$ ardiansyah@tif.uad.ac.id
}

\section{ABSTRAK}

Ibadah merupakan perkara yang penting dalam kehidupan manusia. Kepentingan ini jelas dalam Al-Quran yang menjelaskan penciptaan manusia adalah untuk mengabdikan diri kepada Allah, menurut survai yang di lakukan oleh Nurillah (2013) evaluasi dan motivasi sangat berkaitan erat itu dibuktikan dengan angka 0,839 menunjukan bahwa hubungan yang sangat kuat dan signifikan dari probabilitas $0,000<0,05$. Maka dari itu peningkaan kemampuan dari berrawal dari upaya manusia untuk melaukan evaluasi atau muhasabah terhadap amal dan aktivitas yang dilakukan. Muhasabah juga dapat mempengaruhi fluktuasi keimanan dalam beribadah dengan evaluasi ibadah dapat digunakan sebagai pendukung manusia unuk membantu mengontrol dan mengelola ibadah dalam memotivasi umat muslim dengan cara meriwayatkan ibadah harian yang telah dialakukan. Berdasarkan permasalahan tersebut, maka dibuat suatu penelitina untuk mengembangkan native front-end aplikasi Mutaba'ah menggunakan Android yang membantu umat muslim dalam mencatat ibadah harian dengan mudah dan di mana saja sehingga dapat memudahkan umat muslim dalam mengevaluasi diri untuk dapat memotivasi diri dalam meningkatkan keimanan.

Metodologi yang digunakan dalam penelitian ini yaitu melakukan pengumpulan data menggunakan metode observasi dan studi pustaka. Kemudian dilakukan analisis data deskripsi kebutuhan userdan deskripsi kebutuhan sistem. Tahapan pengembangan sistem berupa perancangan sistem menggunakan model UML. Implementasi aplikasi memanfaatkan Java Android Framework dan web service. Pengujian sistem dilakukan dengan 2 metode, yaitu Black Box Test dan Alpha Test.

Hasil dari penelitian ini adalah sebuah aplikasi Mutaba'ah yang diharapkan dapat memotifasi pengguna dalam meningkatkan ibadah dengan melihat grafik ibadah, riwayat ibadah dan melihat persentase pengguna pada grup yang tersedia. Hasil pengujian sistem dengan metode Black Box Test di peroleh hasil 100\% lulus, kemudian dari hasil pengukuran kepuasan pengguna dengan nilai rata-rata SUS responden 73,50(Acceptabel).

Ciptaan disebarluaskan di bawah lisensi CC-BY-SA.

Kata kunci: Android, Mutaba'ah, Evaluasi ibadah, ibadah.

\section{Pendahuluan}

Ibadah merupakan perkara yang penting dalam kehidupan manusia. Kepentingan ini jelas tertutlis dalam AL-Quran yang menjelaskan penciptaan manusia adalah untuk mengabdikan diri kepada Allah (Salasiah et al., 2012). Menurut Nurillah (2013) muhasabah atau intropeksi diri merupakan pengalaman beribadah yang berkaitan dengan motivasi. Dalam ceramah yang di sampaikan oleh KH.M.Arifin Ilham pada TvOne (2016) menjelaskan bahwa bagi sebagian orang, sudah beriman kepada Allah Subhanahu wa ta'alaa saja sudah merasa cukup. Rasulullah Shallallahu 'alaihi wasallam bersabda "Iman itu kadang naik kadang turun, maka perbaharuilah iman kalian dengan la ilaha illallah." (HR Ibn Hibban). Iman yang ada dalam hati kita mengalami fluktuasi. 
Karenanya, kita harus meningkatkan keimanan dengan cara mengikuti pengajian, merenungkan tanda kebesaran Allah SWT, mempelajari ilmu agama yang bersumber pada Al Quran dan hadist dan mengevaluasi diri, supaya kita dapat termotivasi dalam beribadah kepada Allah SWT. Saat ini yang dilakukan untuk memotivasi diri dalam beibadah pada masyarakat umum adalah aplikasi Evaluasi ibadah dan aplikasi Mutaba'ah sedangkan pondok pesantren Ma'had Aly Putri Isy Karima yang ada di daerah Karanganyar adalah Aplikasi Mutaba'ah thafiz AL-QURAN juz 27 dan thafiz ALQURAN juz 30. Aplikasi evaluasi ibadah dan aplikasi Mutaba'ah tidak menampilkan ibadah yang terkategori sesuai jenisnya, sedangkan aplikasi Mutaba'ah thafis merupakan aplikasi evaluasi ibadah secara khusus thafiz AL-QURAN saja sehingga ibadah yang lainya belum terkendali dengan baik.

Aplikasi Mobile merupakan teknologi yang sudah menjadi bagian yang sangat penting bagi masyarakat. Bentuknya yang kecil dan portabel memudahkan pengguna untuk membawanya kemana saja. kecanggihan Aplikasi mobile pada media online juga dapat digunakan dan dijalankan tanpa banyak kendala dan fitur-fitur media sosial yang terpasang dipiranti smartphone. Pengguna smartphone dapat memasang dan menjalankan berbagai aplikasi yang tersedia di internet dan non internet yang sesuai dengan sistem operasi yang digunakannya.Pada penelitian ini akan dikembangkan aplikasi evaluasi ibadah untuk mengawasi ibadah agar berjalan sesuai dengan yang direncanakan sehingga diharapkan dapat meningkatkan ibadah dengan cara mengevaluasi ibadah dengan mlihat riwayat ibadah atau aktivitas dalam bentuk grafik.

\section{Metode Penelitian}

Agar menunjang pencarian fakta dan pengumpulan data guna pemecahan masalah yang berkaitan dengan kasus ini, maka diperlukan pemahaman bagaimana sistem tersebut nantinya bisa dijalankan. serta untuk mengetahui bagaimana sistem berjalan, diperlukan beberapa metode penelitian untuk memperoleh data yang akurat dan menghasilkan Aplikasi mutaba'ah untuk evaluasi ibadah harian berbasis android yang sesuai adalah dengan menggunakan metode pengumpulan data dalam penelitian ini adalah sebagai berikut:

1. Studi Pustaka

Metode studi pustaka ini dilakukan untuk mendapatkan beberapa data yang terkait dengan penelitian, data berasal dari dokumen-dokumen seperti buku evaluasi ibadah dengan topik yang terkait dalam kasus aplikasi Mutaba'ah.

2. Observasi

Dari hasil observasi yang dilakukan pada aplikasi yang sudah ada diperoleh data sebagai berikut:

a. Pengguna mengisi form pendaftaran akun.

b. Pengguna memilih tanggal yang akan diisi.

c. Pengguna mengisi ibadah harian.

d. Pengguna melihat laporan ibadah harian.

\section{Hasil Penelitian}

\subsection{Perancangan Sistem}

a. Use Case Diagram

Untuk mendapatkan gambaran mengenai system yang akan di buat maka digunakan proses dan data model dari system yang di modelkan dengan diagram use case. Dengan diagram use case ini dapat di ketahui fungsi yang di gunakan oleh system, dibawah ini merupakan gambaran system yang akan di buat.

Gambar use case diagram system aplikasi Mutabaah menjelaskan pengguna adalah actor dalam system aplikasi Mutabaah yang dapat melakukan proses diantaranya dapat digambarkan pada use case diagram detailnya sebagai berikut: 


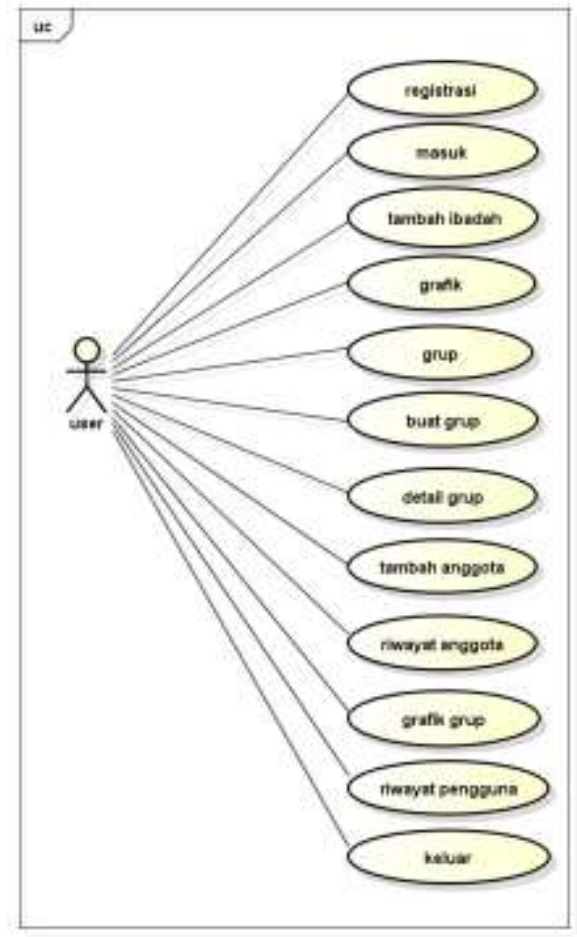

Gambar 3.1 :Use case diagram.

Gambar use case diagram menggambarkan bahwa pengguna sebagai actor dalam aplikasi Mutabaahyang dapat melakukan proses registrasi, melakukan proses masuk, melakukan proses input ibadah, melihat grafik presentase ibadah yang dilakukan, melihat riwayat ibadah yang telah di lakukan serta melakukan proses keluar pada system aplikasi Mutaba'ah.

\section{b. Activity Diagram}

Berkaitan dengan use case diagram yang telah di buat, maka dapat digambarkan beberapa activity diagram dari masing-masing use case diagram tersebut.

c. Sequence diagram

Sequence diagram menjelaskan interaksi objek yang disusun dalam suatu urutan waktu. Diagram ini secara khusus berasosiasi dengan use case. Sequence diagram memberikan tahap demi tahap apa yang harus terjadi untuk menghasilkan sesuatu yang dilakukan use case. Berikut merupakan bentuk-bentuk sequence diagram dari sistem yang dibuat.

d. Class diagram

Class diagram menggambarkan struktur dan deskripsi class beserta hubungannya satu sama lain. Beberapa class yang terdapat dalam class diagram ini adalah user,grup,anggota data_ibadah dan ibadah.

\subsection{Perancangan Database}

a. Tabel pengguna

Tabel pengguna pada penelitian ini untuk menyimpan pengguna yang tersedia pad database sehingga dapat di authentikasi pada saat pengguna melakukan masuk. Tabel pengguna yang digunakan sebagai berikut 
Tabel 3.1 : tabel pengguna.

\begin{tabular}{|l|l|l|l|}
\hline \multicolumn{1}{|c|}{ Field } & Tipe & Panjang & Keterangan \\
\hline Id & Int & 11 & KEY \\
\hline Penggunaname & VARCHAR & 255 & \\
\hline Email & VARCHAR & 255 & \\
\hline Password & VARCHAR & 255 & \\
\hline Created_at & Timestamp & & \\
\hline Updated_at & Timestamp & & \\
\hline
\end{tabular}

b. Tabel ibadah

Tabel ibadah adalah tabel yang mennyimpan data dari pengguna field yang telah lemakukan oencatatan ibadah sehingga tersimpan dalam table ibadah dengan data waktu, id_data, dan nilai yang terdapat dalam tabel sebagai berikut.

Tabel 3.2 : tabel ibadah.

\begin{tabular}{|l|l|l|l|}
\hline \multicolumn{1}{|c|}{ Field } & Tipe & Panjang & Keterangan \\
\hline Id_data & int & 11 & key \\
\hline Nilai & Int & 1 & \\
\hline Waktu & Timestamp & & \\
\hline Id_pengguna & Int & 11 & \\
\hline Id_ibadah & Int & 11 & \\
\hline Created_at & Timestamp & & \\
\hline Updated_at & Timestamp & & \\
\hline
\end{tabular}

c. Tabel grup.

Tabel grup adalah tabel yang menyimpan data dari grup seperti nama grup dan id grup yang terdapat dalam tabel sebagai berikut :

Tabel 3.3 : tabel grup.

\begin{tabular}{|l|l|l|l|}
\hline Field & Tipe & Panjang & Keterangan \\
\hline Id_grup & Int & 100 & KEY \\
\hline Nama & Varcar & 255 & \\
\hline Id_pengguna & Int & 11 & \\
\hline
\end{tabular}

d. Tabel anggota.

Tabel anggota adalah tabel yang menyimpan data anggota dari grup yang tedapat dalam tabel sebagai berikut :

Tabel 3.4 : tabel anggota.

\begin{tabular}{|l|l|l|l|}
\hline Field & Tipe & Panjang & Keterangan \\
\hline Grup & Int & 100 & KEY \\
\hline Anggota & Int & 100 & KEY \\
\hline
\end{tabular}

e. Tabel data ibadah.

Tabel data ibadah adalah tabel yang menyimpan data ibadah ibadah dari aktivitas ibadah yang terdapat dalam tabel sebagai berikut :

Tabel 3.5 : tabel data ibadah.

\begin{tabular}{|l|l|l|l|}
\hline Field & Tipe & Panjang & Keterangan \\
\hline ID & Int & 11 & KEY \\
\hline IBADAH & Varchar & 50 & \\
\hline
\end{tabular}

\subsection{Implementasi}

Tahap implementasi native front-end adalah proses pengubahan benrtuk desain system ke dalam Bahasa pemrograman tertentu. Dalam penelitian ini bahas pemrograman yang di gunakan 
adalah java. Native front-end ini mengimplementasi desain. Berikut ini adalah gambar aplikasi evaluasi ibadah harian.
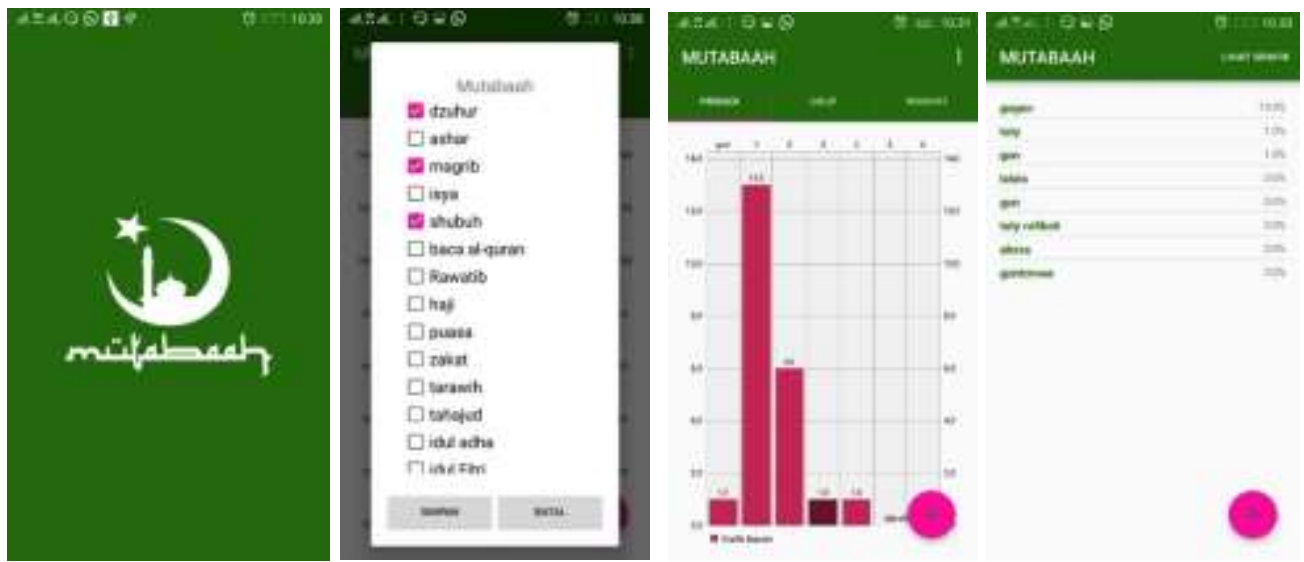

Gambar :3.2 Aplikasi Mutaba'ah untuk evaluasi ibadah harian

Setelah pengeditan teks selesai, naskah siap untuk template. Gandakan file template dengan menggunakan perintah Save As, dan gunakan konvensi penamaan yang ditentukan oleh konferensi Anda untuk nama naskah Anda. Dalam file yang baru dibuat ini, sorot semua konten dan impor file teks yang Anda siapkan. Anda sekarang siap untuk menata naskah Anda; gunakan jendela scroll down di sebelah kiri toolbar Pemformatan MS Word.

\subsection{Pengujian}

\section{a. Black Box Test}

Pada tahapan ini dilakukan pengujian yang bertujuan untuk mengetahui apakah aplikasi yang telah dibuat dapat memenuhi kebutuhan pengguna serta berjalan dengan baik. Pengujian dilakukan dengan dua tahapan yaitu usability dengan menggunakan metode pengujian Blackbox dan user satisfaction. Berikut dibawah ini hasil pengujian usability menggunakan metode pengujian blackbox terhadap salah satu komponen pada aplikasi Mutaba'ah.Table :3.6 hasil pengujian black box

\begin{tabular}{|l|l|l|l|c|}
\hline $\begin{array}{c}\text { Test } \\
\text { ID }\end{array}$ & \multicolumn{1}{|c|}{ Fungsi } & \multicolumn{1}{|c|}{ Description } & \multicolumn{1}{|c|}{$\begin{array}{c}\text { Expected } \\
\text { Result (output) }\end{array}$} & $\begin{array}{c}\text { Actual } \\
\text { Result }\end{array}$ \\
\hline 1. & Registrasi & $\begin{array}{l}\text { Penggunaname, } \\
\text { emanil, password }\end{array}$ & $\begin{array}{l}\text { Registrasi sebagai } \\
\text { pengguna } \\
\text { Tampil peringatan gagal } \\
\text { registrasi }\end{array}$ & Lulus \\
\hline 2. & Login & $\begin{array}{l}\text { Penggunaname, } \\
\text { password }\end{array}$ & $\begin{array}{l}\text { Masuk sebagai pengguna } \\
\text { Tampil peringatan "gagal } \\
\text { login" }\end{array}$ & Lulus \\
\hline 3. & Tambah ibadah & $\begin{array}{l}\text { Klik menu 'toogle } \\
\text { button dan klik } \\
\text { ibadah yang akan } \\
\text { dipilih. } \\
\text { Klik simpan }\end{array}$ & $\begin{array}{l}\text { Tampil daftar ibadah yang } \\
\text { terdaftar } \\
\text { Data berhasil disimpan }\end{array}$ & Lulus \\
\hline 4. & Grafik & $\begin{array}{l}\text { Pilih menu grafik. } \\
\text { Lulus }\end{array}$ & $\begin{array}{l}\text { Tampil grafik ibadah } \\
\text { pribadi. }\end{array}$ & Lulus \\
\hline 5. & Riwayat. & Pilih menu riwayat & $\begin{array}{l}\text { Tampil riwayat ibadah } \\
\text { pribadi. }\end{array}$ & Lulus \\
\hline 6. & Buat grup. & $\begin{array}{l}\text { Klik menu buat } \\
\text { grup } \\
\text { Nama grup }\end{array}$ & $\begin{array}{l}\text { Tampil menu buat grup } \\
\text { Grup brhasil tersimpan. }\end{array}$ & Lulus \\
\hline
\end{tabular}




\begin{tabular}{|l|l|l|l|c|}
\hline 7. & Tambah anggota. & $\begin{array}{l}\text { Klik 'toogle button } \\
\text { dan klik pengguna } \\
\text { yang akan dipilih. } \\
\text { Klik simpan }\end{array}$ & $\begin{array}{l}\text { Tampil daftar pengguna } \\
\text { dalam bentuk checkbox. } \\
\text { Pengguna berhasil } \\
\text { ditambahkan }\end{array}$ & Lulus \\
\hline 8. & Riwayat anggota. & Klik daftar anggota & $\begin{array}{l}\text { Tampil riwayat ibadah } \\
\text { anggota. }\end{array}$ & Lulus \\
\hline 9. & Grafik grup & Klik lihat grafik & $\begin{array}{l}\text { Tampil grafik ibadah pada } \\
\text { grup. }\end{array}$ & Lulus \\
\hline 10. & Daftar grup. & Klik menu grup & $\begin{array}{l}\text { Tampil daftar grup yang } \\
\text { telah dibuat. }\end{array}$ & Lulus \\
\hline 11. & Detail grup. & $\begin{array}{l}\text { Pilih grup yang } \\
\text { telah terdaftar }\end{array}$ & $\begin{array}{l}\text { Tampil anggota yang telah } \\
\text { terdaftar pada grup. }\end{array}$ & Lulus \\
\hline 12. & Keluar. & Hapus session & Kembali ke halama masuk & Lulus \\
\hline
\end{tabular}

Proses pengujian black box test ini dilakukan oleh seorang programer pada PT. Medika Teknologi Nusantara untuk mengetahui tingkat validasi dan stabilitas native front-end dengan mengamati keluaran dari berbagai maksud. Data penguji yang telah melakukan pengujian terhadap native front-end adalah sebagai berikut:

Tabel :3.7 Data pengujian black boxt test

\section{b. Alpha test.}

\begin{tabular}{|c|l|}
\hline Tester & Pekerjaan \\
\hline Nanag agung nugroho, S.kom & programer \\
\hline
\end{tabular}

Proses pengujian ini dilakukan setelah pengguna menggunakan sistem secara menyeluruh menggunakan pengujian SUS (Software Usabikity Scale). Pengujian dilakukan dengan memberi kuisioner yang terdiri dari 10 item pertanyaan, dengan menggunakan skala likert 5 tingkat. Item ganjil memiliki lima pertanyaan positif dan item genap memiliki 5 pertanyaan negatife. Secara keseluruhan nilai rata-rata skor SUS responden adalah 73.50 yang dapat dilihat pada diagram sebagai berikut.

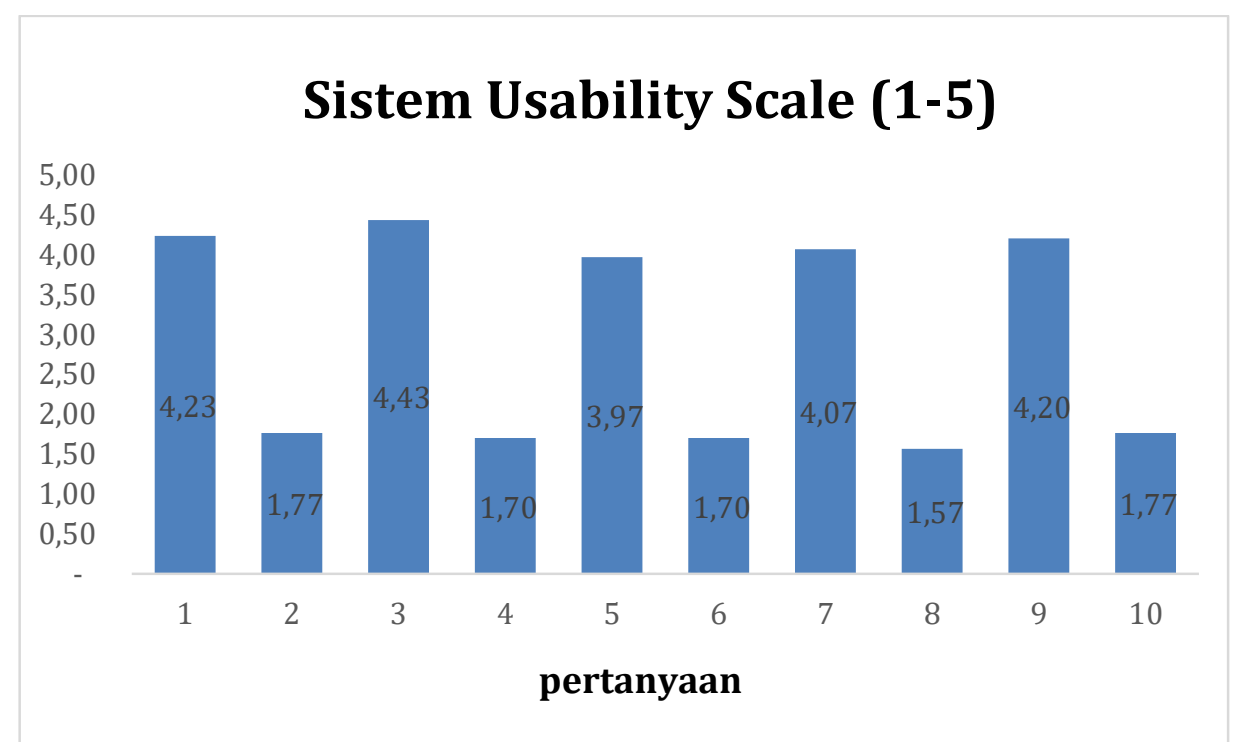

Gambar: 3.3 Diagram SUS

Berdasarkan diagram pada gambar 4.62 nilai tertinggi didapat pada pertanyaan task 3 (pertanyaan positif) dan terendah pada task 8 (pertanyaan negative). 
Rata-rata skor SUS adalah 68 Sauro (2011). Jadi dari perhitungan diatas dapat disimpulkan bahwa nilai rata-rata responden anggota adalah 73.50 maka dinyatakan diatas rata-rata. Berdasarkan skor akhir SUS tersebut akan bias diketahui seberapa tinggi tingkat usability dan akseptabilitas (Acceptabel) desain sistem aplikasi yang dikembangkan. Penilaiannya berdasarkan tiga kategori yaitu Not Acceptabel dengan rentang skor SUS 0-50.9 , Marginal 51-70.9, dan Acceptabel 71-100 (Bangor et al., 2009). Dari perhitungan diatas dapat disimpulkan bahwa nilai rata-rata responden anggota adalah 73,50 maka dinyatakan Acceptabel.

\section{Kesimpulan dan Saran}

\subsection{Kesimpulan}

Berdasarkan hasil penelitian dan pembahasan, dapat di simpulkan beberapa hal sebagai berikut :

1. Penelitian ini telah menghasilkan native front-end aplikasi mutabaah berbasis android

2. Hasil pengujian system yang di lakukan menggunakan metode black box test di peroleh hasil $100 \%$ lulus dan telah berjalan dengan baik, memenuhi kebutuhan pengguna dan mempermudah masyarakat umum dalam mencatat ibadah yang telah dilakukan dengan melihat grafik dan riwayat serta dapat memotifasi pengguna lain dengan mengelompokan pengguna dalam fitur grup.

3. Telah dikembangakan aplikasi yang dapat melakukan pencatatan atau rekap ibadah yang telah di lakukan dalam waktu 24 jam pada perangkat android.

4. Telah dikembangakan aplikasi yang dapat mengelompokan pengguna dalam suatu aplikasi pencatatan ibadah sehingga di harap dapat memotifasi pengguna lain dalam melakukan ibadah dengan melihat presentase riwayat ibadah maupun melihat grafik.

\subsection{Saran}

Pengembangan aplikasi mutabaah menggunakan android baru mencangkup mencatat ibadah yang di lakukan, melihat presentase ibadah dalam bentuk grafik, mengelompokan pengguna dengan fitur grup, dan melihat riwayat ibadah yang di lakukan. Pada penelitian selanjutnya di harapkan dapat di kembangakan fitur penambahan ibadah yang sesuai dengan pengguna inginkan.

\section{DAFTAR PUSTAKA}

Bangor, A., Kortum, P., \& Miller, J. (2009). Determining what individual SUS scores mean: Adding an adjective rating scale. Journal of Usability Studies, 4(3), 114-123. https://doi.org/66.39.39.113

Khusna, D., Isnanto, R., \& Somantri, M. (2011). Perancangan Aplikasi Pembantu Hapalan Al Qur'an Juz 27 Menggunakan Bahasa Pemrograman Visual Basic. Net. Eprint.Undip.ac.id, 1-6. Retrieved from http://eprints.undip.ac.id/32052/

Nurillah, lulutri. (2013). HUBUNGAN MOTIVASI BERIBADAH DENGAN PENGALAMAN BERAGAMA.

Rahmi, V., \& Cahyana, R. (2015). Pengembangan Aplikasi Bergerak Untuk Memudahkan Muslim Melakukan Evaluasi Ibadah Harian. Jurnal Algoritma, 1-6. Retrieved from http://www.sttgarut.ac.id/jurnal/index.php/algoritma/article/view/195

Salasiah Hanin, H., Zainab, I., \& Noor Shakirah, M. A. (2012). Kaedah penerapan ibadah dalam kaunseling salasiah. Jurnal Teknologi, 59, 87-92.

Sauro, J. (2011). Measuring Usability With The System Usability Scale (SUS). Measuring Usability.

TvOne. (2016). Damai Indonesiaku - Muhasabah diri. Bogor. https://www.youtube.com/watch?v=GItZ3NhFzPQ 